\section{Ponto-geniculo-okzipitale Wellen}

Helga Peter

Marburg, Deutschland

\section{Synonyme}

PGO-Wellen; PGO-Spikes

\section{Englischer Begriff}

ponto geniculo occipital spikes

\section{Definition}

Im Pons generierte EEG-Wellen, die direkt dem Beginn von $\checkmark$,REM-Schlaf" vorausgehen. Sie werden rasch durch das laterale Corpus geniculatum zum okzipitalen Kortex weitergeleitet. Die für die Generierung von PGO-Wellen zuständigen Zellen des Pons werden auch als PGO-on-Neurone bezeichnet. Innerhalb der REM-Phasen sind PGO-Wellen auch mit den Phasen der typischen raschen Augenbewegungen des REM-Schlafs assoziiert. 